ORIGINAL ARTICLE

\title{
Temporal trends, gender, and geographic distributions in child and youth injury rates in Sweden
}

\author{
R Ekman, L Svanström, B Långberg
}

Injury Prevention 2005;1 1:29-32. doi: 10.1136/ip.2003.005074

See end of article for authors' affiliations

....................

Correspondence to: Dr Robert Ekman, Karolinska Institutet Department of Public Health Sciences, Division of Social Medicine, Norrbacka, SE-171 76 Stockholm, Sweden: robert.ekman@phs.ki.se
Objective: Sweden has the lowest child injury mortality rate in the world, 5.2/100 000 for children under 15. This paper describes temporal trends in Sweden, as well as gender related and geographic differences.

Design: The Swedish Cause-of-Death Register (1987-2001) and the Hospital Patient Register (19872002) were used to compare rates for the country as a whole and for discharges aged 0-20 by municipality, using the SEATS time series analysis program.

Results: There was a decrease in the rate of fatal unintentional injuries from 7 to 4 per 100000 for girls and from 16 to 10 per 100000 for boys since 1987. The gap between girls and boys was reduced and boys now have almost the same mortality rate as girls for violence related deaths. Road and other unintentional injuries show a general decrease whereas the pattern for falls varies by age and sex. Self inflicted injuries increased for both sexes, but more for girls. Substantial differences in injury rates between municipalities were also found-up to six times for girls and eight times for boys.

Conclusion: Substantial declines in injury fatalities over time were found, but these were different for boys and girls. There remain substantial differences between municipalities. These data, published in a child injury atlas, have prompted substantial interest among media and the authorities.
G ood health and low mortality in childhood are generally considered to be good indicators of how well a society has addressed the general population's welfare, living conditions, and safety. Many countries are still struggling with high child mortality, although in Sweden the situation has markedly improved over the last century. In a recent international comparison of deaths in the age group 0-14, Sweden now shows the lowest rate: 5.2/100 000 children, followed by the United Kingdom and Italy, both at 6.1. The United States has a rate of 14.1/100 000, and Korea has 25.6. ${ }^{1}$

Sweden regards injury as a public health problem that society as a whole must control. This led to a societal approach to the promotion of safety beginning in the $1950 \mathrm{~s}^{23}$ with the development of injury surveillance, information, education and environmental improvement, along with product safety development. The Joint Committee for the Prevention of Accidents to Children was set up in 1954, succeeded by the National Child Environment Council, and later by the Children's Ombudsman and-for two years-the Child Safety Commission. The Swedish Rescue Services Agency is now responsible for the National Safety Promotion Programme, one of whose tasks is to promote child safety.

Sweden is generally regarded as a homogeneous society and only a few studies have examined possible geographic differences in injuries in Sweden. The long term effects of the use of child restraints in motor vehicles have been investigated, with results varying according to part of the country. ${ }^{4}$ Differences in injury rates between countries, and also between socioeconomically defined areas, have also been reported, ${ }^{5-7}$ but relatively few studies have examined differences within a single country..$^{8-11}$ One of the goals of Sweden's Child Safety Commission was to investigate possible geographic differences, and the Karolinska Institutet was given the task of producing a "child injury atlas". ${ }^{12}$ This paper describes temporal trends as well as and gender related and geographic differences reflected in the Atlas.

\section{METHODS}

The study periods were 1987-2001 for injury mortality and 1987-2002 for hospital discharges. The study population, those from birth to age 20, was 2245843 in 2002: $25 \%$ of the total population.

We used the Swedish Cause-of-Death Register and the Hospital Patient Register. ${ }^{13}$ Sweden has few private hospitals and, according to a report of the Swedish Federation of County Councils in 2004, there are no private hospital beds for children. We report on causes of death and on unintentional and intentional injuries among children and youth discharged from hospital after one or more days of medical care. For discharges, the data are analysed for the

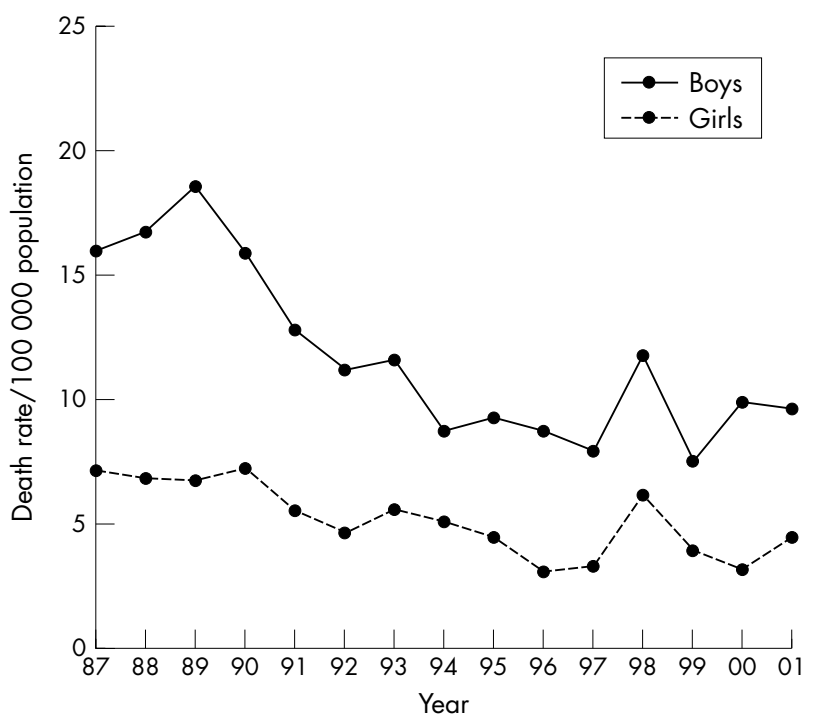

Figure 1 Number of fatal unintentional injuries per 100000 population aged 0-20 in Sweden, by gender, 1987-2001. 




Figure 2 Number of suicides per 100000 population aged 0-20 in Sweden, by gender, 1987-2001.

290 municipalities. Each person was counted only once per year. The proportion of persons hospitalised for more than one injury within the same year was estimated to be low and should not have influenced the results.

The number of fatalities per 100000 children/year is presented by cause of death and gender only for the country as a whole. Injury incidence was defined as the number discharged from hospital per 1000 children/year within each geographic area.

Hospital data were analysed by age group (0-12, 13-20) and by gender. Trends were estimated using Signal Extraction in ARIMA Time Series (SEATS), a computer program developed by Gómez and Maravall in 1996. Modelling programs of this kind are employed within the European Union as recommended by EUROSTAT. ${ }^{14}$ The rates for unintentional and intentional injuries by gender and aged $0-20$ by municipality was described for 2000 , illustrated using maps (see fig 5 in results), and are based on subjects' parish registered place of residence (home municipality) not on the place where injury occurred. However, Swedish studies indicate that place of injury usually coincides with home municipality. ${ }^{15}$

Injuries were classified using Swedish versions of the International Classification of Diseases, ninth revision (ICD9; 1987-96) and the ICD10 (1997-; see Appendix). ${ }^{16}$ The current report is based on the child injury atlas. ${ }^{12}$

\section{RESULTS}

\section{Mortality and morbidity}

There were 3904 child and youth deaths due to injury over the study period, an average of 260 per year. Another 363576 sustained hospitalised injuries during the period, an average of 22723 per year.

\section{Temporal trends}

We found a decrease over time in fatal unintentional injury rate between 1987 and 2001: from 7 to 4 per 100000 for girls and from 16 to 10 per 100000 for boys. The gap between girls and boys was reduced. The gender pattern is the same for suicides, and for violence, boys now have almost the same mortality rate as girls (figs 1-3).

The overall injury incidence over time shows a decrease, similar for the two genders and the two age groups (fig 4).



Figure 3 Number of fatal violence related injuries per 100000 population aged 0-20 in Sweden, by gender, 1987-2001.

However, for fall injuries there was an increase in both sexes under 13, but a decrease among girls aged 13-20.

Self inflicted injuries increased for both genders, but mostly for girls (from 2.1 to 2.6 per 1000). There was no significant change in violence related injuries but the rates were consistently low.

\section{Geographic differences}

Examination of the injury distribution revealed substantial differences between geographic areas in 2000. Among the municipalities, the rate differed almost eight times for boys and six times for girls (fig 5).

\section{DISCUSSION}

Sweden's Cause-of-Death Register is of high quality with regard to completeness, coverage, and coding routines. Although the primary aims of maintaining a register of hospital discharges are administrative and financial, such a

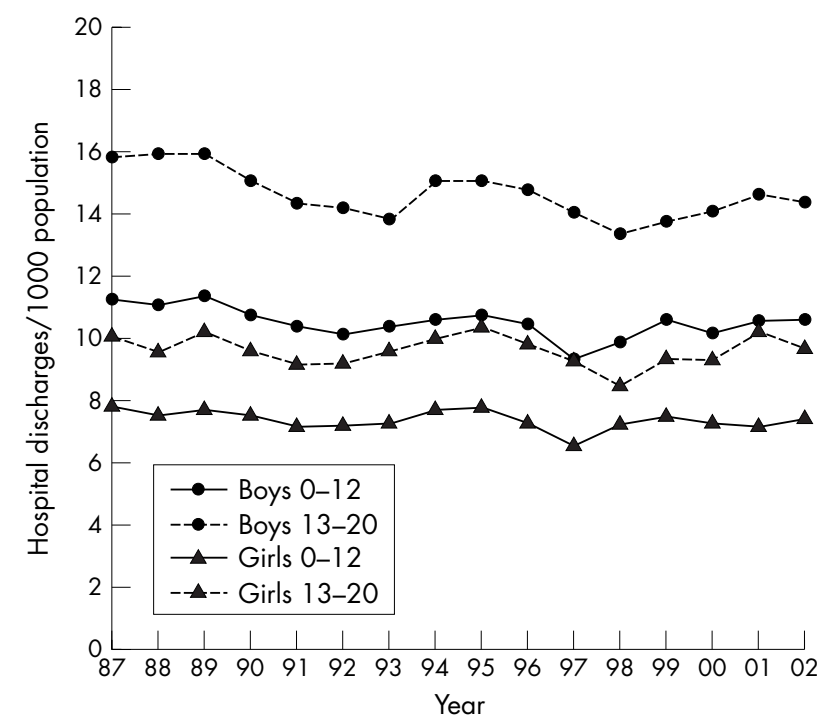

Figure 4 Number of hospital discharges due to unintentional and intentional injuries per 1000 population aged 0-20 in Sweden, by age group and gender, 1987-2002. 

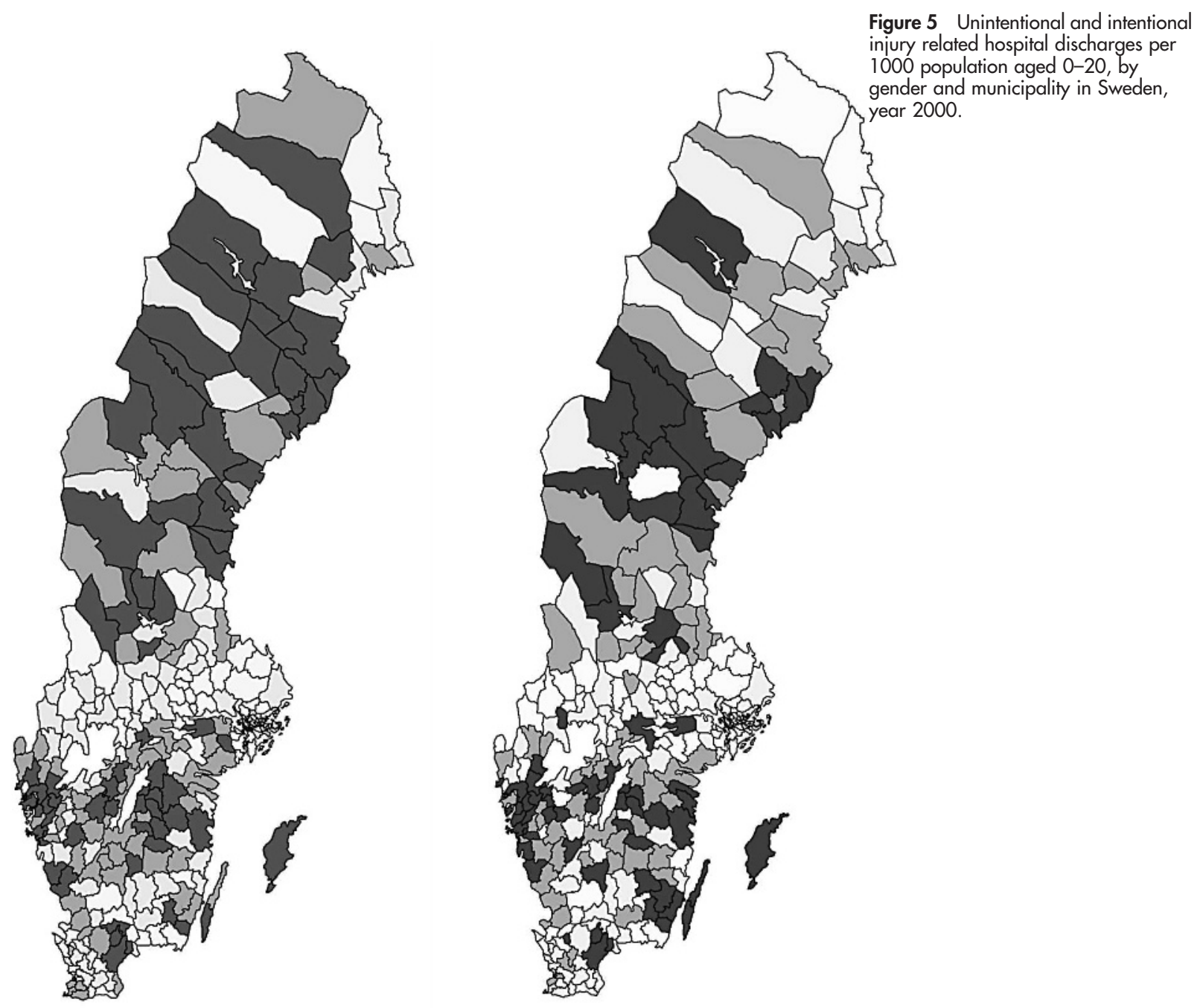

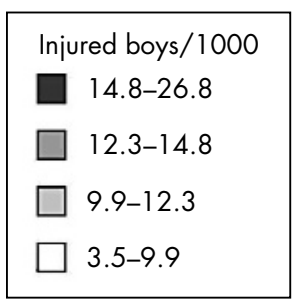

register is also valuable for research. The number of hospital stays in 2001 was 770000 , of which 114000 were attributable to injury. The proportion of missing cases (nonregistered injuries) is estimated to be less than $1 \% .^{13}$

The main explanation for the declining mortality and morbidity rates probably lie in the increasingly favourable economic and social conditions in Sweden. Another important aspect, however, may be the application of a national strategy for safety promotion. This has taken the forms of improvements in the traffic infrastructure, child restraint systems, bicycle helmet use, safety planning in residential areas, swimming competence, use of life vests in recreational maritime activities, availability of public child health care for all, and increasingly skilled emergency services.

Interpretation of the hospital discharges is complicated by possible changes in admission policies, therapeutic technologies, and diagnostic coding practices over time. While such

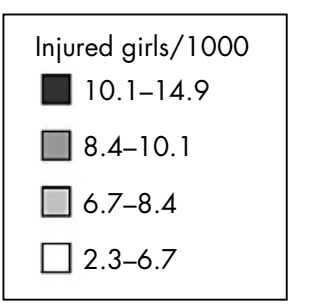

changes may have been effected during the study period it is likely that they were implemented in a similar manner nationwide. However, there may be some differences between counties and hospitals in Sweden with regard to data completeness and coding practices. We adjusted all data series by correcting for any deficiencies found. Accordingly, methodological errors should not influence the main findings. However, changes in the coding system cannot be excluded.

The aim of this study was to publish the results as an injury atlas and thus increase awareness of the existence of registry data and the opportunities available to use injury statistics for discussions about preventive action. The results summarised in this study provide a factual base for measures to be taken by government agencies, municipalities, county councils, and voluntary organisations. The study shows differences in injury incidence over time that differ between 


\section{Key points}

- There was a decrease in the rate of fatal unintentional injuries.

- The gap between girls and boys due to fatal injuries was reduced.

- Boys now have almost the same mortality rate as girls for violence related deaths.

- Road and other unintentional injuries show a general decrease.

- Self inflicted injuries increased for both sexes, but more for girls.

- Substantial differences in injury rates between municipalities - up to six times for girls and eight times for boys.

sexes. There are also differences between municipalities. The trends and the geographical differences call for further analysis.

\section{Implications for prevention}

The injury atlas has attracted the attention not only of the local and national media in Sweden but also of local authorities. Currently, there are a number of Swedish municipalities and county councils that organise safety promotion and injury prevention activities in accordance with the results of this research.

\section{Authors' affiliations}

R Ekman, Karolinska Institutet, Department of Public Health Sciences, Division of Social Medicine, Stockholm, and Swedish Rescue Services Agency, NCO, Centre for Lessons Learned from Incidents and Accidents, Karlskoga, Sweden

L Svanström, Karolinska Institutet, Department of Public Health Sciences, Division of Social Medicine, Stockholm, Sweden

B Långberg, Stiffelsen Allmänna Barnhuset, Stockholm, Sweden

\section{APPENDIX}

Classification of injuries according to Swedish ICD9 (addition to chapter 17; E codes) and the ICD10 (chapter 20, V01-Y98), by external cause.

\section{Road transport accidents}

ICD9: Motor vehicle accidents 819, bicycle accidents 826, accidents involving another vehicle for road transport 829

ICD10: Transport accidents involving a vehicle primarily designed for road traffic and pedestrian accidents in the road transport area V01-V8119, V82-V8219, V83-V8339, V84V8439, V85-V8539, V86-V8639, V87-V8999

\section{Fall accidents}

ICD9: $880-886,888$

ICD10: W00-W1999

\section{Other accidents}

ICD9: Railroad accidents 807, accidents related to water transport, poisoning accidents $838-866$, unspecified causes to fracture 887 , accidents caused by open fires, accidents in the natural environment, drowning, suffocation, and accidents caused by foreign bodies, 890-928

ICD10: Train accidents V812-V8199, tram accidents V822V8299, industrial vehicles V834-V8399, agricultural vehicles V844-V8499, specialised vehicles V854-V8599, terrain vehicles V864-V8699, water based vehicles V90-V9099, other W20-X5999

\section{Intentional injury}

ICD9: Suicide attempts 950-958, fights and rapes 960-968, police interventions 976 , uncertain whether injury occurred intentionally or non-intentionally $980-988$, acts of war 997998

ICD10: Intentional self destructive acts, assaults by another person, injury events with unclear intention, police interventions and acts of war, X60-Y3699

\section{REFERENCES}

1 Unicef. United Nations Children's Fund. A league table of child deaths in rich nations. Innocenti Report Card, Issue No 2. Florence, Italy: Innocenti Research Centre, 2001

2 Bergman AB, Rivara PR. Sweden's experience in reducing childhood injuries. Pediatrics 1991:88:69-74.

3 Barnmiliörådet (Sweden's Child Environment Council) and Folksam Barnsäkerhetsarbete $i$ Sverige i 35 år. Minnen och erfarenheter för framtiden. (Child safety in Sweden during 35 years. Memories and experiences for the future.) Bohuslänningens Tryckeri AB 1989 (in Swedish).

4 Ekman R, Welander G, Svanström L, et al. Long-term effects of legislation and local promotion of child-restraint use in motor vehicles in Sweden. Accid Anal Prev 2001;33:793-7.

5 Ellsässer G, Berfenstam R. International comparisons of child injuries and prevention programs: recommendations for an improved prevention program in Germany. Inj Prev 2000;6:41-5.

6 Li GH, Baker SP. A comparison of injury death rates in China and the United States, 1986. Am J Public Health 1991;5:605-9.

7 Murray CJL, Lopez AD, eds. The global burden of disease. Boston, Harvard School of Public Health: Harvard University Press, 1996.

8 Waller AE, Baker SP, Szocka A. Childhood injury deaths: national analysis and geographic variations. Am J Public Health 1989;79:310-15.

9 Baker SP, Waller A, Langlois J. Motor vehicle death in children: geographic variation. Accid Anal Prev $1991 ; 23: 19-28$.

10 Brown LH, Khanna A, Hunt RC. Rural vs urban motor vehicle crash death rates: 20 years of FARS data. Prehosp Emerg Care 2000;4:7-13.

11 Welander G, Ekman R, Svanström L, et al. Are there intra-country geographic differences in child bicycle-related injuries in Sweden? J Traffic Med 2001;29:20-8.

12 Child Safety Commission. Barns skador i Sverige. Barnskadeatlas med frekvenser och trender på nationell, läns-och kommunnivå 1987-2000. (Child injuries in Sweden. A child injury atlas, showing rates and trends at national, county and municipal level 1987-2000.) SOU 2002;99 (in Swedish).

13 Swedish National Board of Health and Welfare. Available at: http:// www.sos.se/epc/par/index.htm (accessed 8 December 2003).

14 Banco de Espana. Services to the General Public. Available at: http:// www.bde.es/servicio/software/econome.htm (accessed 25 February 2004).

15 Schelp L. Epidemiology as a basis for evaluation of a community intervention program on accidents. Sundbyberg: Karolinska Institutet, Department of Social Medicine, 1987, Thesis.

16 Swedish National Board of Health and Welfare. Klassifikation av sjukdomar 1987. Systematisk förteckning. Swedish version of the International Classification of Diseases, ninth revision (ICD-9). Stockholm: Nordstedts Tryckeri, 1986.

17 Swedish National Board of Health and Welfare. Klassifikation av sjukdomar och hälsoproblem 1997. Swedish version of the International Statistical Classification of Diseases and Related Health Problems, tenth revision (ICD10). Stockholm: Nordstedts Tryckeri, 1999. 